\title{
X-ray Microanalysis Phase Map on Rare Earth Minerals with a Conventional and an Annular Silicon Drift Detector
}

\author{
Chaoyi Teng ${ }^{1}$, Hendrix Demers ${ }^{1}$, Nicolas Brodusch ${ }^{1}$, Kristian Waters ${ }^{1}$, and Raynald Gauvin ${ }^{1}$ \\ ${ }^{1}$ Department of Mining and Materials Engineering, McGill University, Montreal, Quebec, Canada
}

Rare earth elements (REEs) have become important components in over 200 products across an extensive range of applications, causing the demand for these elements keeping rising and the rare earth industry keeping flourishing [1]. The Nechalacho rare earth deposit, located in the Northwest Territories in Canada, is one of the most important REE sources in the world [2]. The aim of this work is to use one high spatial resolution and high count rate scanning electron microscope/x-ray energy dispersive spectrometry (SEM/EDS) system to characterize rare earth minerals (REMs) in this deposit using phase maps. The Xray microanalysis was achieved by a conventional silicon drift detector (SDD) with $60 \mathrm{~mm}^{2}$ collecting area located on the side of specimen and an annular SDD with a same collecting area inserted below the objective lens. The position of the annular detector provides the shortest working distance and the largest solid angle, allowing the X-ray microanalysis with a count rate as high as 2,000,000 cps and short acquisition time. Because of the high count rate, the relatively low accelerating voltage can be used, providing a high spatial resolution, making the characterisation of small features in micron-scale possible. The traditional EDS elemental map shows distribution of elements, but it cannot provide enough information for phase identification. The problem is more obvious in geological materials, where the samples have numerous micro phases with unknown composition. In order to overcome that, we develop a phase map method using the traditional EDS map and the $f$-ratio method [3]. The method was applied to acquire the compositional information of REM and to show their distribution.

Figure 1 displays the phase map of rare earth ores from the Nechalacho deposit acquired with the annular SDD and the conventional SDD at the same conditions. These maps were obtained with the probe current of $280 \mathrm{pA}$ at an accelerating voltage of $20 \mathrm{kV}$ for 5 minutes, 30 minutes, and 60 minutes. The output count rate of the annular detector can reach $67.6 \mathrm{kcps}$ at this condition, but the conventional detector only produce the output count rate of $2 \mathrm{kcps}$. So with the same acquisition time, the annular SDD can produce a much better map than the conventional SDD. In the phase map, the main phases are identified and labeled, so the phase distribution was easily observed. Furthermore, the high spatial resolution provided by the annular detector allows the characterization of one particle. As shown in Figure 2, the magnification of $1800 \mathrm{X}$ was used and a mixture of multiply phases was observed clearly. All the maps were acquired at a low accelerating voltage of $10 \mathrm{kV}$ for 20 minutes.

The phase map method and the annular SDD were successfully used to judge the efficiency of different separation stages during the REM beneficiation [4].

\section{References:}

[1] Weeks, M.E., The discovery of the elements. XVI. The rare earth elements. Journal of Chemical Education, 1932.9(10): p. 1751.

[2] Sheard, E.R., et al., Controls on the concentration of zirconium, niobium, and the rare earth elements in the Thor Lake rare metal deposit, Northwest Territories, Canada. Economic Geology, 2012. 107(1): p. 81-104. 
[3] Horny, P., Development of a Quantification Method for X-ray Microanalysis with an Electron Microscope. 2006.

[4] Teng, C., Characterization of Rare Earth Minerals Extraction Flowsheet with X-ray Microanalysis at High Spatial Resolution, in Materials and Mining Engineering 2015, McGill University.

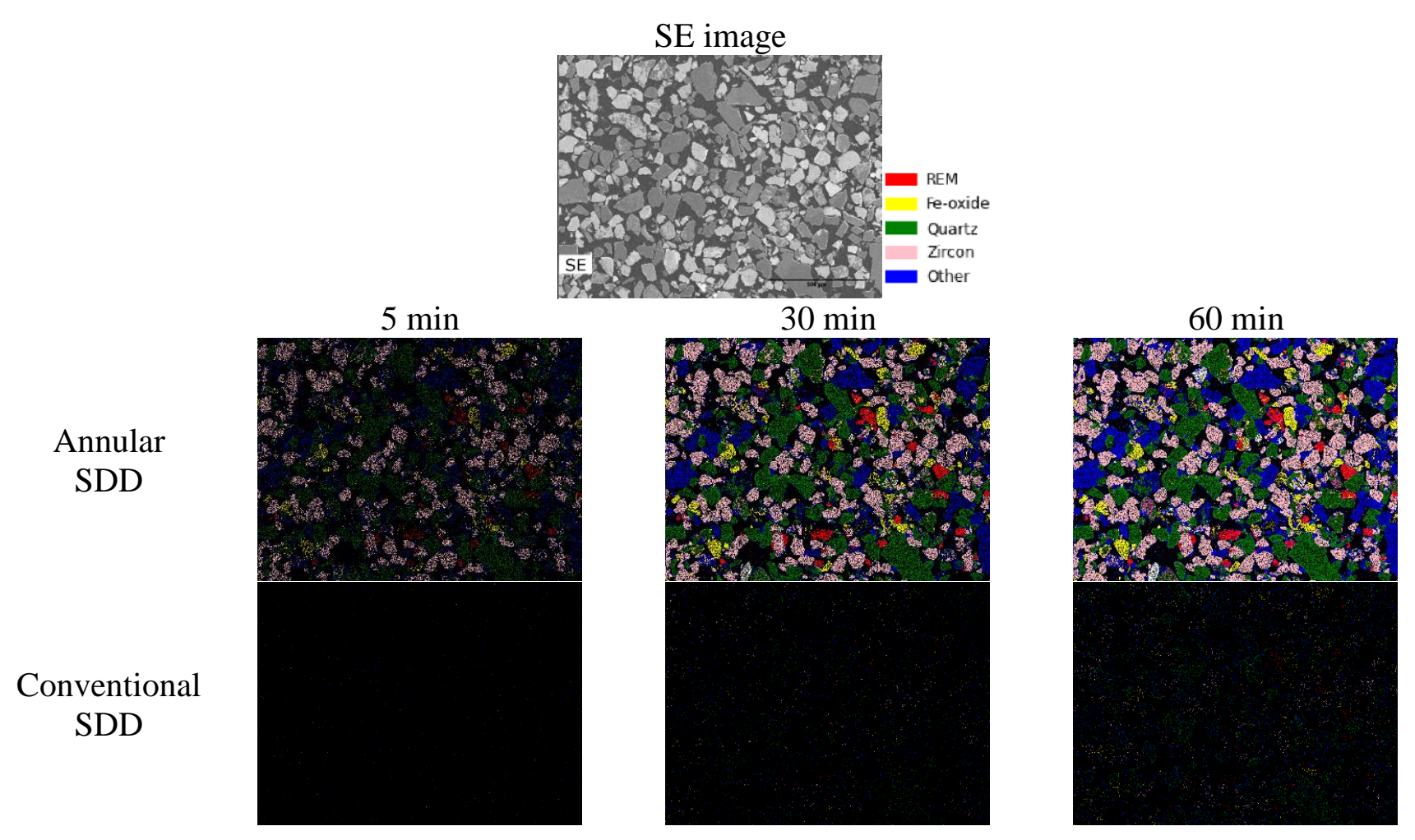

Figure 1. Phase maps of the Nechalacho deposit rare earth ores acquired with the annular SDD and the conventinal SDD for 5 minutes, 30 minutes, and 60 minutes with the same conditions. All the maps were acquired at an accelerating voltage of $20 \mathrm{kV}$.

(a)

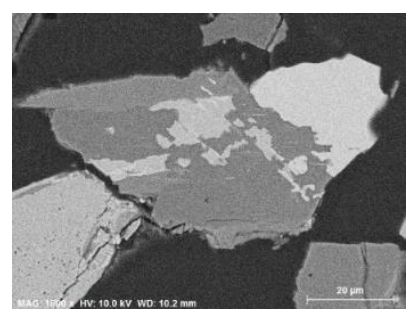

(b)

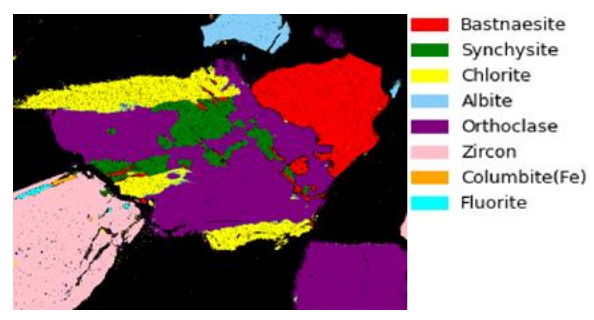

(c)

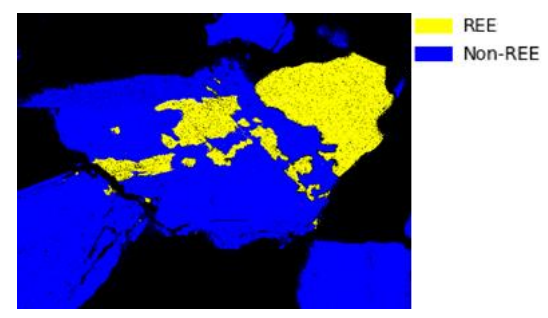

Figure 2. Phase map of the Nechalacho deposit rare earth ores acquired with an annular SDD at an accelerating voltage of $10 \mathrm{kV}$ for 20 minutes. (a) SE image; (b) phase map of all main phases; (c) phase map of phases with and without rare earth. 